\title{
NARRATIVAS DE UM ESTÁGIO EM PSICOLOGIA SOCIAL EM TEMPOS DE PANDEMIA DE COVID-19
}

\author{
Benjamin Dias Pacce ${ }^{1}$ \\ Isadora Garcia De Goes ${ }^{2}$ \\ Edryne Marshall ${ }^{3}$ \\ Rita de Cássia Maciazeki-Gomes ${ }^{4}$
}

Resumo: $\mathrm{O}$ artigo tem por objetivo refletir sobre nossa experiência como estagiários de Psicologia Social em tempos de pandemia do COVID-19. O escrito parte das narrativas produzidas com a participação de atividades remotas junto a Associaçáo de Usuários de Saúde Mental de Pelotas (AUSSMPE). Das dificuldades de estagiar em meio à pandemia, emergem problematizaçóes relacionadas à formação em psicologia, as práticas de cuidado produzidas em meio às telas, as mobilizaçóes em prol da garantia de direitos e a manutenção das políticas públicas de saúde mental. Diante das muitas limitaçóes impostas pela COVID-19, no ano de 2020, nos voltamos para a necessidade de construir práticas inovadoras em Psicologia que consigam transformar a realidade mesmo que por meios virtuais.

Palavras-chave: Psicologia Social, estágio, pandemia de COVID-19, luta antimanicomial, relato de experiência.

\section{NARRATIVES OF AN INTERNSHIP IN SOCIAL PSYCHOLOGY IN TIMES OF THE COVID-19 PANDEMIC}

\begin{abstract}
The article aims to discuss our experience as Social Psychology trainees in times of the COVID-19 pandemic. The writing starts from the narratives produced with the participation of remote activities with the Association of Mental Health Users of Pelotas (AUSSMPE). From the difficulties of internships in the midst of the pandemic, problematizations emerge related to training in psychology, the care practices produced amidst the screens, the mobilizations in favor
\end{abstract}

1 Universidade Federal do Rio Grande (FURG).

2 Universidade Federal do Rio Grande (FURG).

3 Universidade Federal do Rio Grande (FURG).

4 Doutora em Psicologia e professora adjunta da FURG. 
of guaranteeing rights and the maintenance of public mental health policies. In view of the many limitations imposed by COVID-19 in 2020, we turned to the need to build innovative practices in Psychology that are able to transform reality even if through virtual means.

Keywords: Social Psychology, internship, COVID-19 pandemic, anti-asylum fight, experience report.

\section{INTRODUÇÃO}

$\mathrm{O}$ artigo tem por objetivo refletir e compartilhar nossa experiência como estagiários de Psicologia Social em tempos de pandemia do COVID-19 junto à Associação dos Usuários de Saúde Mental de Pelotas (AUSSMPE). Ao longo do texto contextualizamos as mudanças e adaptaçôes que se fizeram necessárias para dar continuidade à formaçáo em Psicologia, em especial os impactos em relação à realização do estágio em Psicologia Social e as estratégias utilizadas para enfrentar esse momento de pandemia.

Detectada em 31 de dezembro de 2019, em Wuhan, na China, a COVID-19 é uma doença infecciosa, altamente transmissível, causada pelo novo coronavírus (SARS-CoV-2). A Organizaçáo Mundial da Saúde (OMS) confirmou a circulação do novo coronavírus em 9 de janeiro de 2020 e em 11 de março, do mesmo ano, decretou estado de emergência sanitária (WHO, 2020). De rápida disseminação e contágio, o novo coronavírus se configurou numa pandemia e levou o planeta a uma crise sanitária, econômica e humanitária sem precedentes. A situaçáo pandêmica impôs novas regras de circulação e convivência social estabelecidas a partir de protocolos municipais e estaduais (RIO GRANDE, 2020; RIO GRANDE DO SUL, 2020). Entre os efeitos à saúde causados pelo novo coronavírus estão as doenças respiratórias graves, sendo transmitido através da inalação de gotículas de saliva e de secreçôes respiratórias que podem ficar suspensas no ar quando a pessoa infectada tosse ou espirra (BRASIL, MEC, 2020a). Os sintomas mais comuns apresentados são: tosse seca, cansaço e febre; sintomas mais graves como dificuldade de respirar ou falta de ar, dor ou pressão no peito e perda de fala ou movimento são muito perigosos e, em alguns casos, exige internamento nas Unidades de Terapia Intensiva (MOREIRA, 2020).

Em 18 de março de 2020 são suspensas as atividades de ensino de modo presencial (BRASIL, MS, 2020). No mês de abril de 2020, o Brasil já estava vivenciando os impactos da COVID-19 na superlotação dos leitos de UTI (G1, 2020). Isso levou a importantes medidas de contenção da disseminação do vírus, como o distanciamento social, prevenção de aglomeraçóes e o uso de Equipamentos de Proteção Individual (EPI), principalmente recomendação para o uso de máscaras, por toda a população (AQUINO, et al., 2020). Devido às medidas de contingência da COVID-19, assim como as atividades de ensino, a realização do estágio de Psicologia Social de forma presencial tornou-se inviável.

Diante das especificidades do cenário imposto pela atual crise sanitária, o Conselho Federal de Psicologia (CFP) e a Associaçáo Brasileira de Ensino de Psicologia (ABEP) lançam um caderno com orientaçôes à comunidade acadêmica 
relacionadas às "Práticas de estágios remotos em Psicologia no contexto da pandemia da Covid-19" (CFP, 2020), autorizado pelo Ministério da Educaçâo (MEC) desde 16 de junho de 2020 (BRASIL, MEC, 2020b). Neste caderno está detalhada a diversidade de possibilidades de atuaçáo profissional em psicologia e a necessidade de se adaptarem em resposta à pandemia, sendo que as práticas de estágio também precisaram passar por ajustes e adaptaçôes de modo a acompanhar os processos de trabalho em Psicologia durante a pandemia. Dentre os processos de trabalho em articulação com as práticas de formação em estágio, estão listadas: investigação científica; trabalhos educativos; gestão e desenvolvimentos de pessoas em contextos de trabalho; prevenção e promoção de saúde e bem-estar; clínicos; avaliação psicológica; orientação e aconselhamento; organizativos de coletivos sociais; mediação de conflitos; proteção social e desenvolvimento; e ensino da psicologia. Para cada uma dessas alternativas o Conselho sugere práticas de estágio adaptadas às políticas tomadas para conter o avanço da pandemia, no sentido de viabilizar a formação dos estudantes (CFP, 2020).

O Projeto Político Pedagógico do Curso de Psicologia da FURG (2012) estipula dois estágios obrigatórios supervisionados ofertados anualmente: o estágio em Psicologia Social (a ser realizado no quarto ano com carga horária total de $360 \mathrm{~h}$ ) e o Estágio em Psicologia Clínica e da Saúde (a ser realizado no quinto ano com igual carga horária). O estágio em Psicologia Social deve ser realizado dentro dos serviços ligados às Políticas Públicas de Saúde, Educação e Assistência Social (MACIAZEKIGOMES; D'AVILA; SANTOS, 2020). Na assistência social o psicólogo compõe a equipe dos Centros de Referência em Assistência Social (Cras) e dos Centros de Referência Especializado em Assistência Social (Creas) (CFP, 2013); na saúde o profissional da psicologia participa dos níveis primário, secundário e terciário do sistema do SUS: Unidades Básicas de Saúde, Unidade de Pronto Atendimento, e, Hospitais respectivamente (CFP, 2019a). Na educação a psicologia se faz presente nas escolas pela Política Nacional de Educação (CFP, 2019b)

A proposta de estágio preconiza o diálogo e compartilhamento de fazeres junto a outras áreas do conhecimento como a medicina, enfermagem, educação, serviço social, entre outras áreas do conhecimento de modo a pensar estratégias e direçóes do cuidado psicossocial. No que se refere à saúde mental, a principal referência de apoio é a Rede de Apoio Psicossocial (RAPS) que é composta por serviços financiados pelo Ministério da Saúde por meio do SUS.

A pandemia da COVID-19 impactou de maneira significativa o funcionamento das atividades nos serviços da RAPS, uma vez que adotadas as medidas de segurança para o controle da proliferação do vírus foram suspensas as práticas de cuidado que envolvem o contato físico e territorializado que aconteciam em grupo. Um estudo realizado pela Organização Mundial da Saúde (WHO, 2020) em 130 países mostrou que $93 \%$ deles tiveram serviços essenciais de saúde mental interrompidos durante a pandemia de COVID-19, mostrando que essa descontinuidade nos serviços presenciais de saúde mental ocorreu em diversos países do mundo. No Brasil, uma pesquisa com dois Centros de Atenção Psicossocial Infantojuvenil (CAPSi) do Distrito Federal registrou uma baixa significativa da circulaçáo de usuários pelo 
serviço (FONSECA, et al., 2020; DA COSTA, et al., 2020). Profissionais da região sul da Bahia relataram que diante da necessidade do isolamento social a circulação nos CAPS ficou restrita somente à renovação das receitas médicas e atendimento técnico restrito ao manejo das situaçôes de agudização dos sintomas (CRUZ, et al., 2020). Como (re)pensar as práticas de estágio em Psicologia neste contexto? Como compor práticas de cuidado em meio à pandemia de COVID-19? Como dar continuidade a formação em Psicologia? Diante desse cenário, pensar em um estágio em Psicologia Social à distância inicialmente foi (e ainda é no momento da escrita deste texto) um processo muito desafiador, visto que o trabalho antes realizado a partir do contato físico com pessoas e coletivos não seria mais uma opçáo viável neste período.

Em setembro de 2020, nos deparamos com a volta às atividades acadêmicas curriculares que passaram a acontecer de modo remoto, mediadas pelas tecnologias da comunicação, à distância. E junto acompanhamos a interrupção e/ou diminuição da oferta de serviços de saúde mental presenciais no Brasil e no mundo, ao passo que surgem formas inovadoras de cuidado e intervenção psicológica em saúde mental em formato digital (WHO, 2020).

No processo de remodelação das propostas de estágio para o formato remoto, surgiu a possibilidade de estagiar junto à Associação dos Usuários dos Serviços de Saúde Mental de Pelotas (AUSSMPE). A Associação foi criada em 13 de agosto de 2002 e, com quase 20 anos de existência, é composta e coordenada por pessoas que têm sua história atravessada por atendimentos em instituiçóes de saúde mental, seja na perspectiva psicossocial ou manicomial. A AUSSMPE preconiza os princípios da luta antimanicomial, a desinstitucionalização, a desospitalização em prol de um cuidado em liberdade (DUARTE, 2017). Valoriza os saberes vindos da experiência das pessoas que recebem o cuidado em saúde mental, que possuem sua trajetória de vida marcadas pelo estigma da loucura, sendo diagnosticadas com alguma doença mental. A Associação baseia sua atuação ancorada nas novas abordagens em saúde mental (BENEVIDES, et al., 2010) valoriza a expertise por experiência (TOURETTE-TURGIS; PEREIRA-PAULO, 2016), segue em luta para que as vozes de quem é considerado "louco" sejam ouvidas, e seu saber sobre seu sofrimento e sua subjetividade sejam valorizados e os direitos preservados e ampliados.

O grupo, de modo auto gestionário, participa de manifestaçóes, compóe grupos terapêuticos e se insere nas discussóes que envolvam as Políticas Públicas do município. Devido à pandemia, essas atividades tiveram que ser repensadas e seguiram acontecendo através de videoconferências e grupos em aplicativos de mensagem, em um funcionamento totalmente remoto. Através de meio digital ocorrem, semanalmente e/ou a cada quinze dias, os grupos terapêuticos organizados pela associação como: o Grupo de Gestáo Autônoma da Medicação (GAM), o Grupo dos Ouvidores de Vozes e o Grupo de Ajuda e Suporte Mútuo abertos à comunidade. A Associação também participa da Comissão Municipal de Saúde em que reivindica e se posiciona frente às pautas relacionadas: ao sucateamento dos Centros de Atenção Psicossocial; à composição de estratégias de cuidado em liberdade; ao fechamento dos Hospitais Psiquiátricos; à falta de medicamentos na 
farmácia municipal; às demandas para implementação de um CAPS III na cidade, que acolha ao público em situação de crise durante 24 horas.

Durante o estágio, realizado de setembro de 2020 até maio de 2021, tivemos a possibilidade de acompanhar essas atividades e construir relaçóes colaborativas e de aprendizado mútuo. As atividades em grupo propostas pela AUSSMPE têm raiz no empoderamento dos usuários dos serviços de saúde mental, com ênfase nas relaçôes pautadas na autonomia para tomada de decisóes desde a direção de seus tratamentos de saúde até o planejamento de suas vidas. $\mathrm{O}$ movimento também busca ampliar a produção de relaçôes mais horizontais entre usuários e profissionais da saúde mental.

Para compreender a história do presente traçada pelo movimento da AUSSMPE, se faz necessário historicizar brevemente a constituição da Psiquiatria como ciência, o surgimento dos manicômios, o domínio da loucura e a produçáo do sujeito "louco". Em seguida, traçamos uma história do presente com enfoque nos movimentos da Reforma Psiquiátrica nos quais a AUSSMPE está inserida.

\subsection{O SURGIMENTO DA PSIQUIATRIA, DOS MANICÔMIOS E DOS MOVIMENTOS SOCIAIS PELA REFORMA PSIQUIÁTRICA}

A Psiquiatria nasce no contexto da França Revolucionária, a partir de reformas nas instituições sociais e desde seu nascimento ela sofre críticas e reformas. $\mathrm{O}$ advento de uma nova ciência da mente traz consigo um discurso médico que se apropria da loucura, passando a ser definida como uma doença mental (AMARANTE, 1996). Nas palavras de Foucault (1972), "a loucura [...] vai ser reduzida ao silêncio pela era clássica através de um estranho golpe de força." (pg. 52). A psiquiatria passa a atrelar a loucura à doença mental, através de um conhecimento "científico", em que o doente mental é um sujeito considerado juridicamente incapaz e uma perturbação para a sociedade, sendo necessárias técnicas de exclusão pautadas na estigmatização da loucura e da internação (FOUCAULT, 1972).

Grandes espaços de internamento são criados a partir do século XVII, os chamados Hospitais Gerais, e neles são confinados os considerados marginalizados, delinquentes, pervertidos, miseráveis e loucos. Foucault denomina essa prática e período como A Grande Internaçáo (FOUCAULT, 1972), esse espaço em que havia grande soberania e supremo direito de execução, local voltado para reclusão e correção, considerado como de assistência pública. Os alienados lá mantidos são considerados como violentos e perigosos pela sociedade, e no âmbito da filosofia tidos como desprovidos de razão. O Hospital Geral consolida-se como uma instituição médica em que há produção e exercício do saber médico, e é com o confinamento dos loucos nesses locais para análise e tratamento de suas loucuras que surge a Psiquiatria (AMARANTE, 1996).

No Brasil, as primeiras instituiçóes psiquiátricas foram criadas por volta do fim do século XIX e início do século XX. Nos anos 1930 foram adotadas práticas como o choque insulínico, o choque cardiazólico, a eletroconvulsoterapia e a lobotomia 
ao tratamento dos pacientes. O manicômio se tornou o espaço de referência para o tratamento psíquico (DIAS; MUHL, 2020). Registros históricos indicam que pelo menos 70\% dos internados no Hospital Colônia de Barbacena não tinham sequer diagnóstico de transtorno mental, sendo o manicômio um espaço de tratamento desumano, de tortura e de assassinato em massa (ARBEX, 2013; BARRETO, 1993; BRAGA, 2013).

Ideias e debates sobre uma reforma da psiquiatria existem desde seu surgimento como ciência, mesmo que tratadas com outros nomes. No entanto, é somente após a Segunda Guerra Mundial que esses movimentos de reforma adquirem bases teóricas, técnicas e administrativas e esse campo se consolida como disciplina denominada publicamente como reformas psiquiátricas (AMARANTE, 1996).

Com o surgimento do Movimento dos Trabalhadores em Saúde Mental (MTSM) no final dos anos 1970, os movimentos brasileiros de luta antimanicomial e de Reforma Psiquiátrica começam a se fortalecer (FIGUEIRÊDO; DELEVATI; TAVARES, 2014; DIAS \& MUHL, 2020). O movimento reivindicava transformaçóes na assistência em saúde mental com denúncias das opressóes derivadas da institucionalização da loucura e propunha o cuidado em liberdade. O movimento pautava mais do que mudanças técnicas na assistência, remontando discussões em relação à loucura e psiquiatria desde um campo teórico, social, cultural e político, adentrando a questáo da cidadania, por muitas vezes negada às pessoas com sofrimento psíquico.

Amarante (1996) ressalta que os projetos de reforma não são homogêneos entre si e o que os diferencia é como cada projeto lida, como práxis e teoria, com a desinstitucionalizaçáo. Destacamos duas principais categorias, dentro dos movimentos de reforma: i) a Psiquiatria de Setor e a Psiquiatria Preventiva, conhecido também como Saúde Mental Comunitária, ii) Antipsiquiatria (AMARANTE, 2011).

O movimento de Saúde Mental Comunitária se caracteriza por acreditar que o modelo hospitalar de cuidado em saúde mental está defasado e deve ser substituído pela construção gradual de outros serviços assistenciais, aos poucos diminuindo a importância dos hospitais psiquiátricos. É com esse movimento que surgem noções de regionalização, de trabalho multidisciplinar, de crise, de prevenção e de desospitalizaçáo; esse último é relacionado à reduçáo de entradas nos hospitais psiquiátricos, reduçáo do tempo médio de permanência neles e no aumento das altas. O movimento pregava que, com açóes preventivas, a incidência de doenças mentais diminuiria e assim o manicômio deixaria de ser necessário, juntamente com o protagonismo de serviços comunitários de saúde mental. No entanto, podese afirmar que esses mesmos serviços comunitários reforçavam a existência dos hospitais psiquiátricos, encaminhando clientelas e captando doentes mentais. Esse processo pode ser entendido como uma expansão ainda maior do discurso médicopsiquiátrico, de suas normas e preceitos sociais, como uma espécie de modernização do aparato técnico-discursivo da psiquiatria. (AMARANTE, 2011) 
Já o segundo grupo não se encaixa exatamente no termo "Reforma", tendo em vista que para ele a raiz do problema se encontra no próprio saber psiquiátrico, não apenas em suas instituiçôes assistenciais. Esse movimento busca o rompimento com o paradigma psiquiátrico e se baseia na ideia de que as pessoas consideradas loucas são oprimidas e violentadas não apenas dentro do espaço do hospital, mas pela família e pela sociedade. A experiência considerada 'patológica', na verdade, expóe conflitos e contradiçóes existentes na sociedade na relação com o indivíduo, não se tratando de um problema individual de uma 'mente doente'. O movimento também tece críticas ao método científico de identificação de doenças mentais, que seria importado das ciências naturais para as ciências humanas, as quais possuem naturezas distintas. A crítica se aplica tanto ao saber psiquiátrico quanto ao método supostamente científico que o embasa. Dentro da antipsiquiatria, náo existe a doença mental como objeto natural, mas sim como uma experiência do sujeito em relação com a sociedade. E se não existe 'doença mental' também não existe um tratamento padronizado para ela, o princípio é que a pessoa vivencie sua experiência, e ao terapeuta cabe apenas acompanhar, proteger e auxiliar a pessoa nesse processo (AMARANTE, 2011).

Esses processos de Reforma Psiquiátrica e Antipsiquiatria também refletiram em nosso país e nas políticas públicas de cuidado em saúde mental. Em 2003, no Brasil, surge o Plano Nacional de Humanização (PNH), conhecido como "HumanizaSUS", com o objetivo de enfrentar as relaçôes de poder, de trabalho e de afeto que inibem a autonomia e corresponsabilidade dos trabalhadores de saúde na sua prática e dos usuários do serviço em seu cuidado de si (BRASIL, 2010). No que se refere ao sofrimento psíquico, o HumanizaSUS defende a Reforma Psiquiátrica e o fortalecimento das Redes de Atenção Psicossocial (RAPS) como forma fundamental do cuidado em liberdade.

Durante a formaçáo em Psicologia e na realização do estágio, nos deparamos com distintas abordagens, discursos e práticas que compóem o entendimento de um cuidado em saúde mental. Poderíamos perguntar com Canguilhem (2002): o que vem a ser o normal e o patológico? Considerando que o patológico só faz sentido na relação dos nossos modos de vida com outras vidas. $\mathrm{O}$ normal e patológico são categorias discursivas que só produzem sentido dentro de condiçóes sócio-históricas determinadas. Sendo o sofrimento uma questáo política, o discurso sobre ele vai estabelecer quais experiências devem ser reconhecidas, tratadas e respeitadas e quais devem ser esquecidas, escondidas ou amordaçadas (DUNKER, 2015).

As análises de nossas narrativas da experiência de estágio junto a AUSSMPE demandam um olhar para as noçóes de território e de experiência. $\mathrm{O}$ conceito de experiência é aqui entendido como aquilo que nos acontece e então nos transforma (FOUCAULT, 2012), em nosso trabalho a situamos em relação às noçóes de saber, poder e subjetividade (LÓPEZ, 2011). Essas são próprias da experiência coletiva que nos ajudam a entender os diferentes modos com que a cultura faz dos seres humanos, sujeitos. A formação dos saberes de um tempo, seus dispositivos e sistemas de poder são, em cada época, fundamentais na constituição da experiência histórica de cada sujeito. Assim percebemos que as nossas experiências singulares 
têm sempre raiz numa experiência da cultura, visto que estamos sempre em relaçáo ao outro. Scott (1998) entende que é necessário historicizar as experiências para que se tornem visíveis as posiçóes do sujeito no discurso e compreender como operam os processos discursivos que geram identidades. É preciso analisar a experiência através dos processos históricos que interpelam os sujeitos na construção das suas narrativas.

Já a noção de território significa para Rolnik e Guattari (2006)

um sinônimo de apropriaçáo, de subjetivaçáo fechada sobre si mesma. Ele é o conjunto dos projetos e das representaçóes nos quais vai desembocar, pragmaticamente, toda uma série de comportamentos, de investimentos, nos tempos e nos espaços sociais, culturais, estéticos, cognitivos. (ROLNIK; GUATTARI, 2006, p. 323)

A AUSSMPE se configura como um território imerso em processos de atuação, percepção e construção no conflito entre o discurso hegemônico psiquiátrico, a saúde mental comunitária e a antipsiquiatria. Nós, como estagiários de Psicologia, também nos encontramos imersos nesse campo de disputa, e através desse processo buscamos nos perceber e reconhecer enquanto agentes que também fazem parte das possibilidades de encontros dentro do território. Assim, através do presente relato, buscamos compartilhar e discutir nossa experiência e nosso lugar ocupado enquanto indivíduos, enquanto futuros profissionais da saúde mental e enquanto estagiários de Psicologia, atravessados pela pandemia de COVID-19.

\section{METODOLOGIA}

Tais perspectivas apresentadas nos conduzem a uma metodologia que difere da ordem prescritiva e protocolar, nos levando a um caminho cartográfico e trabalhando com uma inversão da ordem da pesquisa positivista. Náo se trata de um trabalho baseado em regras rígidas e pré-definidas e nem de um caminho sem direção, mas sim uma metodologia que traça, no caminho, suas próprias metas (PASSOS; BARROS, 2009).

Escolhemos a cartografia como método porque ele prevê a produção de conhecimento a partir da pesquisa participativa como pesquisa-intervenção (PAULON, 2005). Nesse sentido, sujeito e objeto estão juntos na mesma experiência e não é possível assumir uma posição de neutralidade, nos colocando como pesquisadores em uma posição ativa. $\mathrm{O}$ trabalho foi construído entre a experiência do estágio e a pesquisa teórica, se renovando a cada encontro. Nossa pesquisa é também intervenção, e isso nos demandou como pesquisadores uma relação com a experiência em que conhecer e fazer se tornam indissociáveis. Essa metodologia nos possibilitou problematizar a subjetividade e reconhecer se ela reproduz ou não a maneira hegemônica de ser e agir no mundo, problematizar as forças que compóem esse jogo discursivo que constrói experiência e produz realidade (CINTRA et al., 2017). 
Nosso relato de experiência não é apenas um mero registro de informações, mas sim um acompanhamento de processos inventivos e de produção de subjetividades, sendo necessária uma ação de abertura ao movimento do território. Adotamos a processualidade da escrita e buscamos construir com palavras um verdadeiro retorno à experiência do campo, evocando cenas e falas desse campo e falando de dentro dele e não de fora. Reconhecemos que o tempo todo estamos em processos e em conexão com os afetos e forças experienciados nesse campo. Dessa forma, o presente relato reúne tanto informações objetivas sobre os encontros quanto impressōes e associaçóes que emergem na subjetividade do pesquisador quando ele experencia o campo (BARROS; KASTRUP, 2010). Sendo o território a própria experiência do encontro, há a necessidade de estabelecer a valorização da experiência como sendo fator determinante dos espaços e afetos.

Buscamos, através do método cartográfico, colocar nossa experiência em jogo, compartilhar os afetos que circularam e dáo passagem aos acontecimentos agenciados na produçáo coletiva do (re)pensar o processo de estágio. Trazemos resquícios das intensidades evocadas por experienciafetos (MACIAZEKI-GOMES; ORTUÑO, 2020) do fazer-se estagiário/as em Psicologia Social em tempo de pandemia de COVID-19.

\section{RESULTADOS E DISCUSSÁO}

Como estudantes de psicologia, nossa experiência com a interpretação da loucura foi pautada pelos discursos biomédicos e psiquiátricos hegemônicos nas universidades (SOUSA, MACIEL, MEDEIROS, 2018; AMARANTE, 1996; TRAVERSO-YÉPEZ, 2001). O modelo biomédico propóe uma visão cartesiana sobre o paciente que, dentro da dicotomia observador e objeto observado, faz emergir um "distanciamento objetivo" como técnica terapêutica (BARROS, 2002). Também traz consigo a ideia moderna de estratificação do objeto de estudo que é pobre em analisar o funcionamento integral de um sistema, gerando um reducionismo patologizante. Diante dessa interpretaçáo mecanicista do processo saúde-doença temos uma terapêutica que "produz" a doença, olha e busca por ela ao invés de considerar a saúde como investida da sua prática. Dentro da psicologia ainda existem diversas práticas que se aproximam desse modelo positivista e são parte do discurso hegemônico sobre cuidado que influenciou muito nossa concepçáo enquanto psicólogos em formação. A vivência do estágio em meio a AUSSMPE e sua luta antimanicomial foi um momento de choque entre a forma hegemônica de práticas em saúde mental e as práticas defendidas pelas novas abordagens em saúde mental. A experiência de estágio nos levou a problematizar o normal e o patológico e mostrou como é possível praticar psicologia a partir de um movimento éticoestético-político em que o profissional é considerado um agente que se produz nas suas práticas.

O processo da Reforma Psiquiátrica que traz uma Rede de Atenção Psicossocial multidisciplinar e desospitalizada é uma reação à prática de manicomialização das pessoas com sofrimento psíquico. Romper essa lógica manicomial é repensar as 
relações de saber e poder sobre a loucura e se desligar da exclusividade do modelo médico-psiquiátrico incorporando a ideia de um cuidado multidisciplinar. É pensar um cuidado em saúde mental que forneça diferentes possibilidades de existir, além de oferecer psicoterapias e medicamentos. Para isso, não basta apenas desospitalizar e desinstitucionalizar, é preciso ocupar e também produzir novos espaços e territórios.

Percebemos, nas reunióes com a AUSSMPE, o desejo do grupo de possuir um espaço próprio em que pudessem ser realizadas as atividades que são coordenadas pelos membros participantes. Antes da necessidade dos encontros de forma remota, as reuniôes aconteciam em espaços alugados ou cedidos por um sindicato da cidade. Também vivemos junto à AUSSMPE a sua articulação e discussóes junto à Universidade Federal de Pelotas e a Universidade Católica de Pelotas, a fim de construir um projeto um CAPS III, com funcionamento 24 horas para o atendimento à população na cidade. Se concretizado, o projeto institui um lugar com atendimento ao público 24 horas para a pessoa em crise, que não o Hospital Espírita de Pelotas (HEP). O fechamento desse hospital psiquiátrico é uma das principais pautas da Associação e efetuá-lo seria uma grande vitória. Uma fala de um dos participantes da AUSSMPE nos marcou muito em relação a isso: "é desumano lá dentro [no hospital psiquiátrico]".

Percebemos que a Associação flutua entre os movimentos de Antipsiquiatria e de Saúde Mental Comunitária. Apesar da luta por esse fechamento do hospital psiquiátrico, percebemos que além disso a Associação busca abrir novos espaços de cuidado humanizado junto à RAPS do município. Como não há CAPS com funcionamento ao público 24 horas por dia, se alguém necessita com urgência de um serviço de saúde mental, essa pessoa não encontra ajuda no CAPS para além do horário comercial. Isso acaba levando as pessoas que precisam de cuidado em saúde mental em uma situação de emergência a buscarem o hospital psiquiátrico da cidade.

Podemos perceber isso na fala "precisamos do CAPS 24 horas porque a gente náo agenda o nosso surto", que ressalta que a necessidade de cuidado humanizado em saúde mental pode ocorrer a qualquer hora, não apenas de segunda à sexta das $8 \mathrm{~h}$ às $18 \mathrm{~h}$. Além disso, segundo os membros da Associação, não raro o CAPS encaminha pessoas para o hospital psiquiátrico. Ou seja, apesar dos serviços da RAPS do município promoverem cuidado em liberdade, de muitas formas o seu modelo atual se complementa juntamente com o modelo manicomial, reforçando a existência do hospital psiquiátrico ao encaminhar pessoas para lá e não oferecendo cuidado de modo integral.

Entendemos que o modelo da RAPS, apesar de se encaixar dentro da Reforma Psiquiátrica, se configura como complementar ao hospital psiquiátrico. Pois ela opera na lógica em que o saber psiquiátrico hegemônico náo é questionado, mas visa-se apenas a redução da hospitalização e aumento das altas. Assim, esse viés de Reforma Psiquiátrica pode acabar expandindo ainda mais os tentáculos do discurso hegemônico da psiquiatria. Percebemos como esse discurso ainda se desenvolve nos meios sociais e institucionais da cidade quando observamos a sólida hegemonia do 
hospital psiquiátrico como serviço de referência em saúde mental, apesar de haver pelo menos cinco CAPS e uma Associação de Usuários ativa na luta antimanicomial.

Nessa rede de forças, lembramos que ainda é possível encontrar no site da Associação Brasileira de Psiquiatria - referência em cuidado em saúde mental no país - o parecer de 2011, que considera antiético a atuaçáo dos CAPS no atendimento das pessoas com transtorno mental (CONSELHO FEDERAL DE MEDICINA, 2011). Essa crítica é baseada em uma visão de saúde mental presa à noção biomédica de saúde, que desconsidera o papel fundamental que as outras áreas do conhecimento têm na promoção e prevenção da saúde nos serviços substitutivos. Isso demonstra o quanto ainda é preciso reivindicar o reconhecimento do avanço expressivo que o cuidado em rede promoveu no que se refere à um cuidado mais humanizado, e o quanto o território do cuidado em saúde mental é um campo de disputa entre diferentes discursos de saber-poder.

Participar e acompanhar de perto essas lutas e disputas nas quais a AUSSMPE está inserida provocou muitos atravessamentos, mobilizações e afetos em nossos corpos. Fomos mobilizados pelo desejo dos participantes de que os objetivos do grupo se concretizassem. Segundo Rolnik e Guattari (2006), o desejo não se reduz à relação desejo-desejado, mas sempre agencia multiplicidades e constrói territórios, ele é produção. Dessa forma, nos percebemos também desejando o fechamento do HEP, mas não apenas isso; desejando que a Associação obtenha vitórias e reconhecimento; desejando que a luta antimanicomial seja mais difundida pela cidade; desejando que as pessoas internadas no HEP obtenham cuidado em liberdade.

Ao longo de todos os nossos encontros com a AUSSMPE, percebemos atentamente a vivência desse território, nos termos de Rolnik e Guattari (2006), que em nossa vivência do estágio não possui um espaço físico específico mas se dá no meio virtual. Ainda assim, é um local em que circulam afetos e desejos, que os participantes da Associação e nós estagiários nos sentimos em casa.

Nesse movimento, saímos do território de estudantes de psicologia tomados pelos saberes hegemônicos, nos desterritorializamos e nos possibilitamos entrar no território da AUSSMPE. Essa desterritorialização foi um tanto desestabilizadora, mobilizando medos e preocupaçóes, afetos que muitas vezes nos acompanharam ao longo de nosso tempo no estágio. Na nossa experiência, foi inicialmente assustador sair da posiçáo discursiva do saber hegemônico, e tentador permanecer nele. Para exemplificar esse movimento, destacamos uma fala que ouvimos de uma das participantes, em um momento que ainda estávamos tentando entender qual era o nosso lugar e o que nos cabia fazer como estudantes de psicologia no território da AUSSMPE:

"Eu tenho um sonho... será que estou sonhando demais? O que tu me diz, futura psicóloga?"

Nesse momento, muitos questionamentos se atravessaram dentro de nós, e debatemos isso na supervisão semanal: o que eu deveria responder? Como posso dizer a alguém que essa pessoa está sonhando demais? Pode alguém sonhar demais? Pode alguém 
não poder sonhar demais? Poderia ser esse sonho muitas vezes o que a faz seguir em frente, dia após dia? E quem sou eu para dizer se esse sonho é "apropriado" ou não? Que tipo de profissional eu estou me tornando ou quero me tornar? Quem é essa futura psicóloga e o que significa ser uma futura psicóloga?

Percebemos que essa pergunta posta pela participante é uma pergunta que atravessa toda a Psicologia, que constituiu um fazer e uma posição discursiva de dizer como alguém deve pensar, sentir, funcionar, sonhar, exercendo poder sobre esse alguém. Esse momento nos convidou a refletir sobre como é o nosso fazer psicológico como estagiários da Psicologia, em que linhas discursivas de constituição desse fazer nós nos situamos ou queremos nos situar. Queremos realmente responder sobre como alguém deve sonhar, exercendo esse poder, ou tomamos outra posiçáo no fazer psicológico, aderindo a outros discursos e formas de existência?

Esses foram disparadores, provocadores e instigadores da nossa prática como estagiários de Psicologia. Era um momento que nos convidava ao desafio da desterritorialização, colocando o seguinte dilema de permanecer no discurso hegemônico ou se permitir desejar outras formas de atuação, se abrir ao movimento do grupo e encontrar outros territórios. Mas, onde há um movimento de desterritorialização, também há um movimento de re-territorialização (HAESBAERT E GLAUCO BRUCE, 2009). E essa desterritorialização era a única forma de nos abrirmos para algo novo, pois ao mesmo tempo que deixávamos de lado um território, adrentávamos e criávamos outros, (des)construímos o que desejamos ser como estudantes de psicologia e o que desejamos ser como profissionais.

Segundo Spinoza (2009), o corpo humano pode ser afetado por outros corpos de diversas formas, e assim sua potência de agir pode aumentar ou diminuir. No início do nosso estágio, muitas vezes nos perguntamos se realmente poderíamos nos sentir afetados ou afetar outros corpos em um estágio realizado à distância. Seria possível realizar psicologia através de uma tela? Sabemos da necessidade e da importância das medidas de prevençáo, mas como um estágio em Psicologia Social parte do princípio da convivência em grupos, temíamos não poder realmente aproveitá-lo, ou sequer aprender sobre a prática do psicólogo com ele.

Durante o estágio e ao final dele descobrimos a resposta para essa questão. Sim, juntamente com os grupos virtuais e o contato com os membros da AUSSMPE nós fomos afetados pelos corpos dos experts por experiência, assim como afetamos os corpos deles também, produzindo um espaço de mútuo aprendizado. Os membros da Associaçáo demonstraram estar felizes com nossa participaçáo, com nosso apoio e inclusive mostrando o desejo de que continuássemos juntos a eles, não apenas durante o período do estágio. Nós também nos vimos desejosos de manter esse contato, preservar os vínculos que construímos com os participantes, laços que se formaram através da escuta, troca de experiências, compartilhamento de vivências - aspectos que a separação através da tela não é capaz de impedir. Nos sentimos potencializados pelo vínculo com os participantes da AUSSMPE e, assim, nossa potência de ação aumentou e nos impeliu a, por exemplo, desenvolver essa narrativa 
sobre o nosso estágio, compartilhando com outros corpos o quanto fomos afetados, para que possamos afetar e potencializar outros também.

\section{CONSIDERAÇÓES FINAIS}

Nossa experiência do estágio em Psicologia Social nos levou a ocupar um território virtual em que acontecia os encontros com a AUSSMPE. A pandemia do Coronavírus afastou a Associação (e todas as outras organizaçôes) do contato direto com os espaços da cidade, mas isso não tornou sua articulaçáo e sua luta menos significativa. A partir de nossas experiências e encontros com o grupo, conseguimos repensar o fazer psicológico diante das contingências impostas pela pandemia. No contato com o território de afetos, trocas e experiências da AUSSMPE, aprendemos que a construçáo da nossa experiência se dá em encontro com a experiência do outro. Nos percebemos imersos em um movimento de devir, visto que cada encontro com outro é sempre um movimento, algo que nos acontece e nos constrói, nos modifica.

Compreendemos que exercer a Psicologia é um movimento ético-político e foi junto da AUSSMPE que nos (des)contruímos: derrubamos concepçôes de que o fazer psicológico se dá de forma vertical e a partir de um discurso patologizante do sofrimento; construímos novos conceitos sobre que psicólogos queremos ser, críticos dos discursos hegemônicos, sensíveis e comprometidos com a produção de práticas mais acolhedoras, que respeitem a singularidade das experiências de vida das pessoas. Buscamos ressaltar a importância da dissolução de modelos hierárquicos no cuidado em saúde mental coletiva, a crítica à institucionalização, a valorização da experiência de quem recebe o cuidado e a defesa de estratégias emancipatórias dessas pessoas. Acreditamos que o trabalho atinge uma dimensão social, em que há a intenção de contribuir para a produção de um fazer psicológico pautado em uma ética de cuidado horizontal, contextualizado e sensível. Urge a necessidade de pensar em novas políticas de saúde mental, novas formas de cuidado que não correspondem às práticas hegemônicas do saber psiquiátrico.

\section{REFERÊNCIAS}

AMARANTE, Paulo. O homem e a serpente: outras histórias para a loucura e a psiquiatria. Editora Fiocruz, 1996.

AMARANTE, Paulo. Saúde mental e atençáo psicossocial. Editora Fiocruz, 2011.

AQUINO, Estela M. L. et al. Medidas de distanciamento social no controle da pandemia de COVID-19: potenciais impactos e desafios no Brasil. Ciência \& Saúde Coletiva [online]. 2020, v. 25, suppl 1 [Acessado 14 Setembro 2021] , pp. 2423-2446. Disponível em: <https://doi.org/10.1590/1413-81232020256.1.10502020>. Epub 05 Jun 2020. ISSN 1678-4561. https://doi.org/10.1590/1413-81232020256.1.10502020.

ARBEX, Daniela. O Holocausto Brasileiro. São Paulo: Geração Editorial, 2013. 
BARRETO, Lima A. D. Dicionário do Hospício: o cemitério dos vivos. Secretaria Municipal de Cultura, Departamento Geral de Documentação e Informação Cultural, Divisão de Editoração: Rio de Janeiro, 1993.

BARROS, Laura; KASTRUP, Virgínia. Cartografar é acompanhar processos. In: PASSOS, E.; KASTRUP, V.; ESCÓSSIA, L. (Orgs.). Pistas do método da cartografia: pesquisa-intervenção e produção de subjetividade (pp. 52-75). Porto Alegre: Sulina, 2010.

BENEVIDES, Daisyanne. et al. Cuidado em saúde mental por meio de grupos terapêuticos de um hospital-dia: perspectivas dos trabalhadores de saúde. Interface - Comunicaçáo, Saúde, Educação [online]. 2010, v. 14, n. 32 [Acessado 14 Setembro 2021] , pp. 127-138. Disponível em: <https://doi.org/10.1590/S141432832010000100011>. Epub 05 Jan 2012. ISSN 1807-5762. https://doi.org/10.1590/ S1414-32832010000100011.

BRAGA, André Luiz de Carvalho. O Serviço Nacional de Doenças Mentais no governo JK: a assistência psiquiátrica para o Distrito Federal. 2013. Dissertação (Mestrado em História das Ciências e da Saúde) - Fundação Oswaldo Cruz. Casa de Oswaldo Cruz, Rio de Janeiro, RJ, 2013.

BRASIL. Ministério da Educação. Portaria n³43. Dispóe sobre a substituição das aulas presenciais por aulas em meios digitais enquanto durar a situação de pandemia do Novo Coronavírus - COVID-19. Diário Oficial da Uniáo, n53, Brasília-DF, 17 de jun. p.39, 2020c.

BRASIL. Ministério da Educação. Portaria n ${ }^{\circ} 544$. Dispóe sobre a substituição das aulas presenciais por aulas em meios digitais, enquanto durar a situação de pandemia do novo coronavírus - Covid-19, e revoga as Portarias MEC no 343, de 17 de março de 2020, no 345, de 19 de março de 2020, e no 473, de 12 de maio de 2020. Diário Oficial da Uniáo, ${ }^{\circ} 114$, Brasília-DF, 17 de jun. p.62, 2020 b.

BRASIL. Ministério da Saúde. Coronavírus e novo coronavírus: o que é, causas, sintomas, tratamento e prevençáo. Brasília, DF. Ministério da Saúde, 2020a. Disponível em: https://www.saude.gov.br/saude-de-a-z/coronavirus, Acessado em 14 de set. de 2021).

BRASIL. Ministério da Saúde. Secretaria de Atenção à Saúde. Política Nacional de Humanizaçáo da Saúde. Documento Base para gestores e trabalhadores do SUS. 4a ed. Brasília, DF. Ministério da Saúde, 2010.

CENTRO DE REFERÊNCIA TÉCNICA EM PSICOLOGIA E POLÍTICAS PÚBLICAS - CREPOP. Referência técnica para atuaçáo de psicólogas(os) nos Centros de Referência Especializada de Assistência Social (Creas). Brasília, DF: Conselho Federal de Psicologia, 2013.

CENTRO DE REFERÊNCIA TÉCNICA EM PSICOLOGIA E POLÍTICAS PÚBLICAS - CREPOP. Referências técnicas para atuaçáo de psicólogas(os) na educaçáo básica. Brasília, DF: Conselho Federal de Psicologia, 2019b. 
CENTRO DE REFERÊNCIA TÉCNICA EM PSICOLOGIA E POLÍTICAS PÚBLICAS - CREPOP. Referências técnicas para atuação de psicólogas(os) na atenção básica à saúde. Brasília, DF: Conselho Federal de Psicologia, 2019a.

CINTRA, Amanda M. S. et al. Cartografia nas pesquisas científicas: uma revisão integrativa. Fractal : Revista de Psicologia [online]. 2017, v. 29, n. 1 [Acessado 16 Setembro 2021] , pp. 45-53. Disponível em: <https://doi.org/10.22409/1984-0292/ v29i1/1453>. Epub Jan-Apr 2017. ISSN 1984-0292. https://doi.org/10.22409/19840292/v29i1/1453.

CONSELHO FEDERAL DE MEDICINA. Define que as Portarias SAS nos 224/92 e 336/02, do Ministério da Saúde, são antiéticas no que tange aos Caps III, ad II e III, vulnerando a segurança da assistência aos pacientes e a prática segura do ato médico, recomendando a adoção de medidas pelo Ministério da Saúde e instâncias judiciais, bem como recomendação aos Conselhos Regionais de Medicina para a adoção das providências cabíveis. CFM no 8.589/10 - Parecer CFM no 1/11. 12 de janeiro de 2011.

CONSELHO FEDERAL DE PSICOLOGIA. Práticas e estágios remotos em psicologia no contexto da pandemia de covid-19: recomendaçóes [recurso eletrônico]. 2020. disponível em: https://site.cfp.org.br/publicacao/praticas-e-estagios-remotos-empsicologia-no-contexto-da-pandemia-da-covid-19-recomendacoes/. Acesso em: $11 \mathrm{de}$ maio de 2021.

CRUZ, Náira; SOUZA, Edilza; SAMPAIO, Catilene; SANTOS, Adriana; CHAVES, Sarita; HORA, Ronoel; SOUZA, Rozemere; SANTOS, Josenaide. Apoio psicossocial em tempos de COVID-19: experiências de novas estratégias de gestão e ajuda mútua no sul da Bahia, Brasil. APS EM REVISTA. 2. 97-105. 2020. 10.14295/aps.v2i2.94.

DA COSTA, Wilson. D.; LIMA, Carla C.; BRANDÃO, Amanda. T.; MESQUITA, Gabrielle. S. IMPACTOS DA PANDEMIA DE CORONAVÍRUS EM UM CAPS INFANTOJUVENIL DO DISTRITO FEDERAL. Health Residencies Journal-HRJ. 2020. 1(1), 1-20.

DUNKER, Christian I. Lentz. Mal-estar, sofrimento e sintoma: uma psicopatologia do Brasil entre muros. São Paulo: Ed. Boitempo, 2015

DUARTE, Rosi Marrero. Lembrar é resistir: Uma etnografia com a AUSSMPE Associação de Usuários dos Serviços de Saúde Mental de Pelotas. 2017. Dissertação (Mestrado em Antropologia) - Programa de Pós-Graduação em Antropologia, Instituto de Ciências Humanas, Universidade Federal de Pelotas, Pelotas, 2017.

FIGUEIRÊDO, Marianna. L. de R.; DELEVATI, Daniel. M.; TAVARES, Marcelo. G. ENTRE LOUCOS E MANICÔMIOS: HISTÓRIA DA LOUCURA E A REFORMA PSIQUIÁTRICA NO BRASIL. Caderno de Graduaçáo - Ciências Humanas e Sociais - UNIT - ALAGOAS, [S. 1.], v. 2, n. 2, p. 121-136, 2014. Disponível em: https:// periodicos.set.edu.br/fitshumanas/article/view/1797. Acesso em: 17 set. 2021. 
FONSECA, Renata. P. O. et al. Da proximidade ao distanciamento social: desafios de sustentar a lógica da atenção psicossocial em tempos de pandemia. Relato de experiência do Centro de Atenção Psicossocial Infantil - CAPSi Asa Norte no Distrito Federal. Brasília. Health Residencies Journal, v.1, n.1, 2020. Disponível em: https:// escsresidencias.emnuvens.com.br/hrj/article/view/21/7. Acesso em: 7 dez. 2020.

FOUCAULT, Michel. História da loucura na Idade Clássica (J. T. C. Netto, trad.). São Paulo: Perspectiva, 1972.

FOUCAULT, Michel. Ditos \& Escritos V. Ética, Sexualidade e Política. Rio de Janeiro: Forense Universitária, 2012.

HAESBAERT E GLAUCO BRUCE, Rogério. A Desterritorialização na Obra de Deleuze e Guattari. GEOgraphia, v. 4, n. 7, p. 7-22, 21 set. 2009.

KIMATI DIAS, Marcelo; MUHL, Camila. Agenciamentos da Psiquiatria no Brasil: Reforma Psiquiátrica e a Epidemia de Psicotrópicos. Argumentum, [S. 1.], v. 12, n. 2, p. 60-74, 2020. DOI: 10.18315/argumentum.v12i2.29114. Disponível em: https:// periodicos.ufes.br/argumentum/article/view/29114. Acesso em: 17 set. 2021.

LÓPEZ, Maximiliano V. O CONCEITO DE EXPERIÊNCIA EM MICHEL

FOUCAULT. Reflexáo e Açáo, Santa Cruz do Sul, v. 19, n. 2, p. 42-55, jul. 2011. ISSN 1982-9949. Disponível em: <https://online.unisc.br/seer/index.php/reflex/article/ view/2367>. Acesso em: 24 set. 2021. doi:https://doi.org/10.17058/rea.v19i2.2367.

MACIAZEKI-GOMES, Rita; D’AVILA, Geruza; SANTOS, Daniela. Reflexões sobre o estágio de Psicologia Social: narrativas de diferentes enfoques do processo de formação. Pesqui. prát. psicossociais, São João del-Rei , v. 15, n. 4, p. 1-16, dez. 2020. Disponível em <http://pepsic.bvsalud.org/scielo.php?script=sci_arttext\&pid=S1809$89082020000400006 \& \operatorname{lng}=$ pt\&nrm=iso $>$. acessos em 14 set. 2021.

MOREIRA, Rafael da Silveira. COVID-19: unidades de terapia intensiva, ventiladores mecânicos e perfis latentes de mortalidade associados à letalidade no Brasil. Cadernos de Saúde Pública [online]. 2020, v. 36, n. 5 [Acessado 14 Setembro 2021] , e00080020. Disponível em: <https://doi.org/10.1590/0102-311X00080020>. Epub 18 Maio 2020. ISSN 1678-4464. https://doi.org/10.1590/0102-311X00080020.

PAULON, Simone M. A análise de implicação com ferramenta na pesquisa-intervenção. Psicologia \& Sociedade [online]. 2005, v. 17, n. 3 [Acessado 19 Setembro 2021] , pp. 18-25. Disponível em: <https://doi.org/10.1590/S0102-71822005000300003>. Epub 10 Mar 2006. ISSN 1807-0310. https://doi.org/10.1590/S0102-71822005000300003.

PROVIDELLO, Guilherme G. D.; YASUI, Silvio. A loucura em Foucault: arte e loucura, loucura e desrazão. História, Ciências, Saúde - Manguinhos [online]. 2013, v. 20, n. 4 [Acessado 19 Setembro 2021] , pp. 1515-1529. Disponível em: <https://doi.org/10.1590/ S0104-59702013000500005>. ISSN 1678-4758. https://doi.org/10.1590/S010459702013000500005 . 
RIO GRANDE. Decreto no 17.045, de 19 de março de 2020. Decreta estado de emergência pública no âmbito territorial do Município do Rio Grande, ante a declaração de pandemia mundial (COVID-19) pela Organização Mundial de Saúde (OMS) - ONU. Diário Oficial de Rio Grande, RS, 2020. Disponível em:https://leismunicipais.com.br/a/ rs/r/rio-grande/decreto/2020/1704/17045/decreto-n-17045-2020. Acesso em 24 de set. de 2021.

RIO GRANDE DO SUL. Decreto no 55.115, de 12 de março de 2020. Dispóe sobre medidas temporárias de prevenção ao contágio pelo COVID-19 (novo Coronavírus). Diário Oficial de Rio Grande do Sul, 2020. Diponível em: https://leisestaduais.com. $\mathrm{br} / \mathrm{rs} /$ decreto-n-55115-2020-rio-grande-do-sul-dispoe-sobre-medidas-temporarias-deprevencao-ao-contagio-pelo-covid-19-novo-coronavirus. Acesso em: 24 de set. de 2021.

SCOTT, Joan W. A Invisibilidade da Experiência. Projeto História, no 16, São Paulo, 1998, p.303-304.

SPINOZA, Baruch. Ética. Belo Horizonte: Editora Autêntica, 2009.

SUPERLOTAÇÃO das UTIs: Fantástico mostra a situação crítica em capitais por causa da Covid-19. G1, São Paulo, 19 de abril de 2020. Disponível em: <https://g1.globo.com/ fantastico/noticia/2020/04/19/superlotacao-das-utis-fantastico-mostra-a-situacao-criticaem-capitais-por-causa-da-covid-19.ghtml>. Acesso em: 11 de maio de 2021.

TOURETTE-TURGIS, Catherine.; PEREIRA-PAULO, Lennize. RECONHECER A EXPERIÊNCIA E A EXPERTISE DO DOENTE: UM DISPOSITIVO INOVADOR: A UNIVERSIDADE DOS PACIENTES. Revista da FAEEBA - Educaçáo e

Contemporaneidade. 2016. v. 25, n. 46, 11.

TRAVERSO-YÉPEZ, Martha. A interface psicologia social e saúde: perspectivas e desafios. Psicologia em Estudo [online]. 2001, v. 6, n. 2 [Acessado 19 Setembro 2021] , pp. 49-56. Disponível em: <https://doi.org/10.1590/S1413-73722001000200007>. Epub 10 Jan 2005. ISSN 1807-0329. https://doi.org/10.1590/S141373722001000200007.

WHO - WORLD HEALTH ORGANIZATION. The impact of COVID-19 on mental, neurological and substance use services: results of a rapid assessment. Disponível em: https://www.who.int/publications/i/item/978924012455. Acesso em: 15 junho 2021. 